\title{
Molecular evidence that Carex songorica Kar. \& Kir. and C. gotoi Ohwi (Cyperaceae) are distinct species
}

\author{
Irina Shekhovtsova * \\ Central Siberian Botanical Garden, SB RAS, 630090, Novosibirsk, Zolotodolinskaya str. 101, Russia
}

\begin{abstract}
Carex songorica and $C$. gotoi have similar appearance, but different distributions that almost do not overlap. Some authors considered $C$. gotoi as a subspecies of $C$. songorica. This opinion was based on the premise that $C$. gotoi differs from $C$. songorica only by slightly narrower utricles with thickened costate veins and somewhat longer beak. In order to clarify the extent of differences between these two taxa, we performed a molecular genetic study based on specimens from Asian Russia. We also re-examined herbarium specimens in order to clarify the correctness of identification and the differences between $C$. songorica and C. gotoi. Our results suggest that these taxa can be considered distinct species.
\end{abstract}

\section{Introduction}

The genus Carex L. (Cyperacea Juss.) is one of the most species-rich and widespread genera in the world flora. It includes over 2000 species $[1,2,3]$.

The section Tumidae Meinsh. contains about 17 species from Europe, moderate zone of Asia, east of North America, south of South America, Northern Africa Australia, and New Zealand [2]. Species of this section inhabit banks of rivers and lakes, swamps, wet and swampy meadows, from the sea level to the middle, sometimes high mountain zones.

Carex songorica Kar. et Kir was described in 1842 by G.S. Karelin and I.P. Kirillov based on collections from Central Asia from the Lepsa river (LE). This species was found to be widespread in the Caucasus, southeastern Turkey, Iran, Afghanistan, West Pakistan, Turkmenistan, Uzbekistan, Kyrgyzstan, Tajikistan, Kazakhstan, Russia (Siberia), northern and eastern Mongolia, China (Dzungaria).

C. gotoi Ohwi was described in 1930 from the Korean Peninsula (KYO). In 1931 V.I. Kreczetovicz described C. sukaczovii V.I. Krecz. from Chita oblast (Russia), which he later on synonymized with $C$. gotoi. C. gotoi was subsequently found in Russia (Eastern Siberia and the Russian Far East), eastern Mongolia, northeastern China and the Korean Peninsula.

$C$. songorica and $C$. gotoi have similar appearance, but different distributions that almost do not overlap. Some authors $[2,4,5]$ considered $C$. gotoi as a subspecies of $C$. songorica, C. songorica subsp. gotoi. This opinion was based on the premise that $C$. gotoi

\footnotetext{
* Corresponding author: maklakovain@mail.ru
} 
differs from $C$. songorica only by slightly narrower utricles with thickened costate veins and somewhat longer beak.

In order to clarify the extent of differences between these two taxa, we performed a molecular genetic study based on specimens from Asian Russia. We used three markers: a fragment of the plastid matk gene, and two fragments of the ribosomal RNA cluster, the external transcribed spacer (ETS) and the internal transcribed spacer 2 (ITS2). These sequences were successfully used in many studies on sedges, e.g., for the closely related section Vesicariae [6]. We also re-examined herbarium specimens in order to clarify the correctness of identification and the differences between $C$. songorica and C. gotoi.

\section{Materials and methods}

Herbarium specimens were taken from the NSK Herbarium. For $C$. songorica, we sampled 10 specimens from distant geographic locations and for C. gotoi, 4 specimens. Details on the specimens are given in Table 1.

Table 1. Sampling points. Reg., region; v., village

\begin{tabular}{|l|l|l|l|}
\hline $\begin{array}{l}\text { Specimen } \\
\text { no. }\end{array}$ & Sampling locality & $\begin{array}{l}\text { Collection } \\
\text { date }\end{array}$ & Collectors \\
\hline \multicolumn{3}{|c|}{ C. songorica } \\
\hline C250 & Khakasia Rep., Bograd d., Beregovoye v. & 19.07 .1969 & G. Pavlova, V. Baranova \\
\hline C251 & $\begin{array}{l}\text { Irkutsk oblast, southern shore of Baikal, } \\
\text { Slyudyanka }\end{array}$ & 04.08 .1974 & A. Kiseleva \\
\hline C 267 & $\begin{array}{l}\text { Tuva Rep., Piy-Khem reg., Eastern Sayan, } \\
\text { Saigara v. }\end{array}$ & 29.07 .1973 & $\begin{array}{l}\text { M. Lomonosova, N. } \\
\text { Iskakova }\end{array}$ \\
\hline C268 & Krasnoyansk krai, Shirokino reg., Sukino v. & 19.07 .1966 & Maskayev, Dyatlova \\
\hline C270 & Altai Rep., Kosh-Agach reg., Kurai v. & 28.08 .1985 & L. Malyshev \\
\hline $\begin{array}{l}\text { C279, } \\
\text { C280 }\end{array}$ & Khakasia Rep., Askiz reg., N. Uzhungul v. & 18.07 .1971 & A. Koroleva, G. Gileva \\
\hline C282 & Khakasia Rep., Askiz reg., N. Uzhungul v. & 26.07 .1971 & $\begin{array}{l}\text { A. Koroleva, T. } \\
\text { Martynova }\end{array}$ \\
\hline C260 & Altai Rep., Ongudai reg., Talda v. & 07.07 .2007 & I.N. Shekhovtsova \\
\hline C062 & Altai Krai, Terekta reg., Kastakhta river & 12.08 .1984 & L. Malyshev \\
\hline \multicolumn{3}{|c|}{ C. gotoi } \\
\hline C252 & Irkutsk oblast, Bayandai reg. Khuty ulus & 08.07 .1956 & $\begin{array}{l}\text { Frolova, Khilova, } \\
\text { Radkevich }\end{array}$ \\
\hline C253 & Buryatia Rep., Eravna reg., Telemba v. & 16.07 .1953 & A. Kurban-Talieva \\
\hline C264 & Chita oblast., Aleksandrovskii zavod v. & 02.07 .1963 & Peshkova, Martynova \\
\hline C265 & $\begin{array}{l}\text { Chita oblast, Olovyannaya reg., Khara-Byrka } \\
\text { v. }\end{array}$ & 21.07 .1961 & G. Peshkova \\
\hline
\end{tabular}

Dried leaves (100-500 mg) were ground in a mortar to fine powder and transferred to an Eppendorf tube with $1 \mathrm{ml}$ of CTAB buffer (3\% CTAB, $1.4 \mathrm{M} \mathrm{NaCl}, 30 \mathrm{mM}$ Tris- $\mathrm{HCl}$ (pH 8.0), $2 \mathrm{mM}$ EDTA) for $4 \mathrm{~h}$ at $65^{\circ} \mathrm{C}$. After incubation, $1 \mathrm{ml}$ of chloroform was added and mixed, and the tube was centrifuged for $5 \mathrm{~min}$ at $16000 \mathrm{~g}$. The supernatant was transferred to a new tube and mixed with an equal volume of isopropanol, incubated for 5 min and centrifuged for $10 \mathrm{~min}$ at $16000 \mathrm{~g}$. The resulting pellet was dissolved in distilled 
water and purified on BioSilica columns (Russia) to remove residual polyphenols interfering with PCR reactions.

DNA amplifications were performed using commercial PCR mix (Biolabmix, Russia). A fragment of the plastid matk gene was amplified using universal primers matK-1 (5'TTCAA-ATCCT-TCAAT-GCTGG-3') and matK-3 (5'-TGAGA-GGAAG-GACTGGAACT-AA-3') from Shekhovtsov et al. (2012). For the external transcribed spacer (ETS), the universal primers ETS-1F (5'-CTGTG-GCGTC-GCATG-AGTTG-3') and 18S-R (5'AGACA-AGCAT-ATGAC-TACTG-GCAGG-3') from Starr et al. (2003) were used. The complete internal transcribed spacer 2 (ITS2) with flanking sequences were amplified using primers CITS2-F2 (5'-CAACG-GATAT-CTCGG-CTCTC-3') and CITS2-R2 (5'-GATTCGCTCG-CCGTT-ACTAT-3') from Shekhovtsov et al. [6]. All DNA fragments were sequenced from both ends.

DNA chromatograms were edited using Chromas v.2.6.6 (Technelysium Pty Ltd). Phylogenetic trees were constructed for the concatenated dataset using MEGA X [7]. For the Maximum Parsimony (MP) algorithm, the Subtree-pruning-regraphing search with 1000 bootstrap repetitions was performed.

\section{Results and discussions}

\subsection{Phylogenetic Analyses}

Table 2. Table 2. Nucleotide substitutions in the studied DNA markers. M stands for C/A; K, for $\mathrm{G} / \mathrm{T}$; R, for $\mathrm{A} / \mathrm{G}$; $\mathrm{Y}$, for $\mathrm{C} / \mathrm{T}$. Numbers indicate positions in the alignment.

\begin{tabular}{|c|c|c|c|c|c|c|c|c|c|c|c|c|c|c|}
\hline Specimen & \multicolumn{4}{|c|}{ ITS2 } & \multicolumn{10}{|c|}{ ETS } \\
\hline & 178 & 225 & 249 & 311 & 98 & 147 & 235 & 255 & 266 & 293 & 358 & 454 & 479 & 521 \\
\hline C. gotoi & & & & & & & & & & & & & & \\
\hline $\mathrm{C} 252$ & $\mathrm{C}$ & $\mathrm{C}$ & $\mathrm{G}$ & $\mathrm{A}$ & $\mathrm{C}$ & $\mathrm{C}$ & $\mathrm{C}$ & $\mathrm{G}$ & $\mathrm{A}$ & A & $\mathrm{G}$ & $\mathrm{C}$ & $\mathrm{A}$ & $\mathrm{T}$ \\
\hline C264 & . & . & . & . & . & . & . & . & . & . & . & . & . & . \\
\hline C265 & . & . & . & r & . & . & . & . & . & . & . & . & . & . \\
\hline $\mathrm{C} 253$ & . & . & . & . & . & . & . & . & . & . & . & . & $\mathrm{R}$ & . \\
\hline $\begin{array}{l}C . \\
\text { songorica }\end{array}$ & & & & & & & & & & & & & & \\
\hline C267 & $\mathrm{T}$ & $\mathrm{M}$ & $\mathrm{K}$ & . & $\mathrm{T}$ & A & $\mathrm{T}$ & A & $\mathrm{C}$ & . & $\mathrm{R}$ & . & G & $\mathrm{C}$ \\
\hline $\mathrm{C} 250$ & $\mathrm{~T}$ & $\mathrm{~A}$ & $\mathrm{~T}$ & . & $\mathrm{T}$ & $\mathrm{A}$ & $\mathrm{T}$ & $\mathrm{A}$ & $\mathrm{C}$ & . & $\mathrm{R}$ & . & $\mathrm{R}$ & $\cdot$ \\
\hline $\mathrm{C} 282$ & $\mathrm{~T}$ & A & $\mathrm{T}$ & G & $\mathrm{T}$ & A & $\mathrm{T}$ & A & $\mathrm{C}$ & $\mathrm{R}$ & $\mathrm{A}$ & $\mathrm{Y}$ & G & . \\
\hline C062 & $\mathrm{T}$ & A & $\mathrm{T}$ & $\mathrm{G}$ & $\mathrm{T}$ & A & $\mathrm{T}$ & $\mathrm{A}$ & $\mathrm{C}$ & $\mathrm{R}$ & $\mathrm{A}$ & . & $\mathrm{G}$ & . \\
\hline $\mathrm{C} 251$ & $\mathrm{~T}$ & A & $\mathrm{T}$ & $\mathrm{G}$ & $\mathrm{T}$ & A & $\mathrm{T}$ & $\mathrm{A}$ & $\mathrm{C}$ & $\mathrm{R}$ & $\mathrm{A}$ & . & G & . \\
\hline $\mathrm{C} 260$ & $\mathrm{~T}$ & A & $\mathrm{T}$ & G & $\mathrm{T}$ & A & $\mathrm{T}$ & $\mathrm{A}$ & $\mathrm{C}$ & $\mathrm{R}$ & A & . & G & . \\
\hline C268 & $\mathrm{T}$ & $\mathrm{A}$ & $\mathrm{T}$ & $\mathrm{G}$ & $\mathrm{T}$ & $\mathrm{A}$ & $\mathrm{T}$ & $\mathrm{A}$ & $\mathrm{C}$ & $\mathrm{G}$ & $\mathrm{A}$ & . & $\mathrm{G}$ & . \\
\hline $\mathrm{C} 270$ & $\mathrm{~T}$ & A & $\mathrm{T}$ & G & $\mathrm{T}$ & A & $\mathrm{T}$ & A & $\mathrm{C}$ & . & A & $\mathrm{T}$ & G & . \\
\hline $\mathrm{C} 279$ & $\mathrm{~T}$ & A & $\mathrm{T}$ & $\mathrm{G}$ & $\mathrm{T}$ & $\mathrm{A}$ & $\mathrm{T}$ & $\mathrm{A}$ & $\mathrm{C}$ & . & $\mathrm{A}$ & $\mathrm{T}$ & $G$ & . \\
\hline $\mathrm{C} 280$ & $\mathrm{~T}$ & A & $\mathrm{T}$ & G & $\mathrm{T}$ & A & $\mathrm{T}$ & A & $\mathrm{C}$ & . & A & $\mathrm{T}$ & G & . \\
\hline
\end{tabular}

For all studied specimens, we obtained sequences of matk (591 bp), ITS2 (438 bp), and ETS (593 bp). No indels were found in any of the genes. The plastid matk sequences of $C$. songorica and $C$. goto $i$ were identical. Four polymorphic sites were found in ITS2, and nine, in ETS (Table 2). Most of these positions delimited C. songorica from C. gotoi. 
Almost no genetic diversity was detected within C. gotoi; only the $\mathrm{C} 253$ had one degenerate position in ETS. For $C$. songorica, on the contrary, many specimens had positions with the variants characteristic for $C$. gotoi.

Both ITS2 and ETS are parts of the ribosomal RNA cluster, and are represented as hundreds of tandemly repeated copies in the genome. Thus degenerate nucleotides represent not two alleles of a single locus located on different chromosomes, as we would normally expect, but the ratio of sequences with different variants within the cluster.

On the phylogenetic tree (Fig. 1) one can see that both taxa form two reciprocally monophyletic groups. As seen in Table 2, C. songorica differs from C. gotoi by as much as four positions in ITS2 and eight, in ETS. This is higher than for many species of sedges. E.g., the species $C$. vesicaria and $C$. vesicata differ by one and four substitutions in these loci, respectively (our data, not shown).

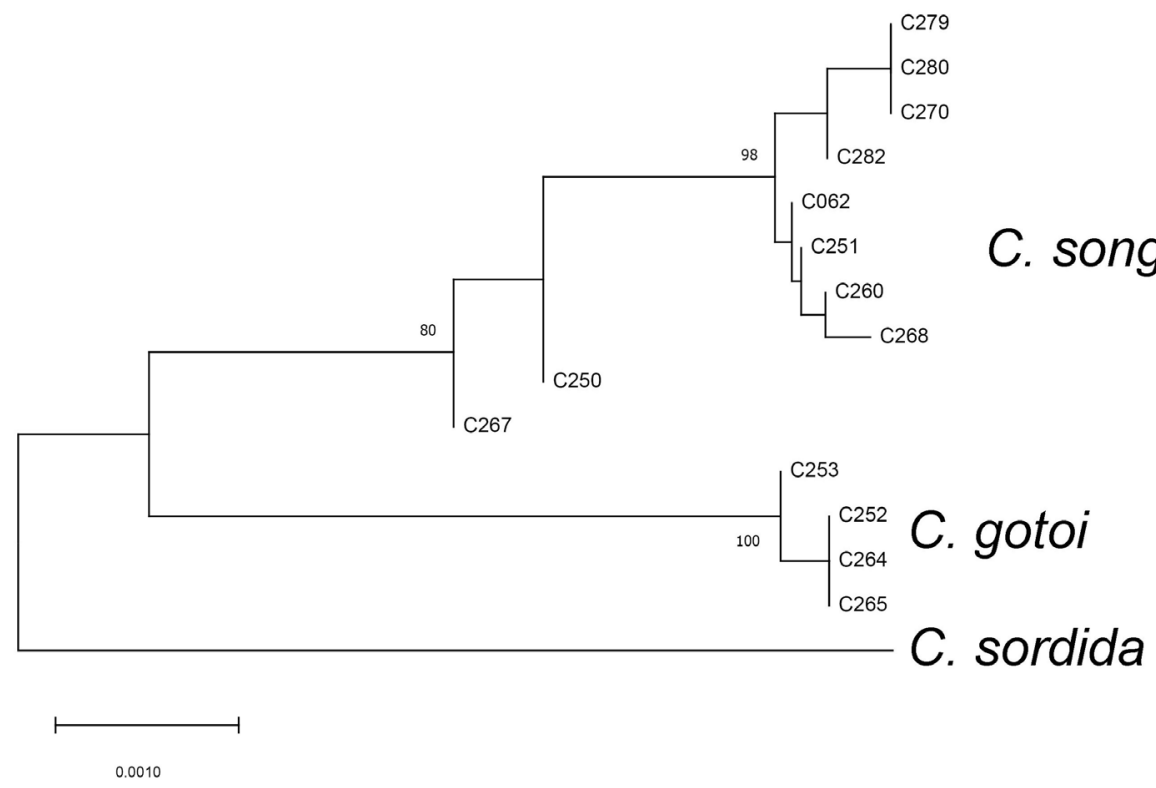

Fig. 1. Minimum Evolution phylogentic tree of C. songorica and C. gotoi. Number near the branched indicate bootstrap support.

\subsection{Morphological comparison}

C. songorica differs from $C$. gotoi by having orange utricles with fine veins and shorter beak $0.5-0.7 \mathrm{~mm}$ long. $C$. gotoi is characterized by dark purple utricles with thicker costate veins and longer beak $(0.8-1.2 \mathrm{~mm})$.

Specimen C252, reported as C. songorica from Irkutsk oblast (Bayanday region, v. Khuty) in the "Flora of Siberia" [5] and in the "Check-list of the Vascular Flora of the Irkutsk region" [8]. Our molecular data indicates that it belongs to C. gotoi. Its morphology is also closer to the latter species.

The Siberian Flora [5] reports C. gotoi from Khakasia (Bidzha river). We consider this to be the result of an erroneous identification, because our specimens from Khakasia (C279, C280, 282, C250) from adjacent regions belong to $C$. songorica.

We can thus conclude that $C$. gotoi и $C$. songorica are characterized by morphological and genetic differences and have different distributions. Although many botanists $[2,4,5]$ 
referred to $C$. gotoi as a subspecies of C. songorica, our results suggest that these taxa can be considered distinct species.

I am grateful to S.V. Shekhovtsov and S.E. Peltek for the help with DNA sequencing. The work was performed as part of the state assignment of the Central Siberian Botanical Garden of the Siberian Branch of the Russian Academy of Sciences on the project AAAA-A17-117012610055-3 "Biological diversity of cryptogamic organisms (algae, fungi, lichens) and vascular plants in the geospace of biotic and abiotic factors, their role in aquatic and terrestrial ecosystems of North Asia". In preparing the publication, materials of the bioresource scientific collection of CSBG SB RAS "Herbarium of Higher Vascular Plants, Lichens and Fungi (NS, NSK)”, UNU № USU 440537 were used

\section{References}

1. A.A. Reznicek, Can. J. Bot., 68, 1409-1432 (1990)

2. T.V. Egorova, The sedges (Carex L.) of Russia and adjacent states (St Petersburg Chem.-Pharmaceut. Acad., Miss. Bot. Gard. Press, 1999)

3. Global Carex Group, Bot. J. Linn. Soc., 179, 1-42 (2015).

4. M.G. Popov, List of plants Herbarium flora of the USSR, 14, 6 (1955)

5. L.I. Malyshev, Flora of Siberia. Cyperaceae (Novosibirsk, Nauka, 1990)

6. S.V. Shekhovtsov, I.N. Shekhovtsova, S.E. Peltek, Nordic Journal of Botany, 30 (3), 343 (2012)

7. S. Kumar, G. Stecher, M. Li, C. Knyaz, K. Tamura, Molecular biology and evolution, 35 (6), 1547-1549 (2018)

8. L.I. Malyshev, Check-list of the Vascular Flora of the Irkutsk region (Irkutsk, Irkutsk State University, 2008) 